\title{
Changes in the Educational Gradient of Fertility Not Driven by Changes in Preferences
}

Daniel Ciganda I ciganda@demogr.mpg.de Angelo Lorenti I lorenti@demogr.mpg.de Lars Dommermuth

This working paper has been approved for release by: Natalie Nitsche (nitsche@demogr.mpg.de), Deputy Head of the Laboratory of Fertility and Well-Being.

(c) Copyright is held by the authors. 


\title{
Changes in the Educational Gradient of Fertility Not Driven by Changes in Preferences
}

\author{
${ }^{1}$, Daniel Ciganda $\square^{1}$, Angelo Lorenti ${ }^{1}$, and Lars Dommermuth ${ }^{2}$ \\ ${ }^{1}$ Max Planck Institute for Demographic Research \\ ${ }^{2}$ Statistics Norway, Research Department
}

\begin{abstract}
Fertility levels have historically been negatively correlated with the amount of information and material resources available to individuals and families. The recent reversal of this trend has been interpreted as a fundamental change in preferences, a return to large families led by more educated individuals. Our analysis shows, however, that the recently documented changes in fertility can be reproduced in the context of declining family size preferences across educational levels, and without assuming any transformation of the underlying behavioral mechanisms that link resources and fertility across cohorts. We demonstrate this point by replicating the stylized facts reported in previous studies using a simulated dataset. We generate this dataset from a model that assumes continuity in the way education shapes reproductive intentions over time. In our simulated population, the reversal in the relationship between education and fertility emerges as a result of the transition from a natural to a regulated fertility regime, as the share of unplanned births decreases over time, and the mechanisms that positively connect educational attainment with desired fertility become dominant. We conclude, thus, that the explanation for the weakening educational gradient of fertility lies primarily in the decline of unintended fertility, instead of in changes in fertility preferences.
\end{abstract}

Keywords - fertility, education, development, computational modeling, simulation, approximate bayesian computation, agent-based modeling, microsimulation, demography, reproductive process.

Acknowledgments: The contribution of Lars Dommermuth was funded by The Research Council of Norway (Grant number 287634). 


\section{Introduction}

In most developed countries, the decline in fertility started in the late $19^{\text {th }}$ century and continued for about a hundred years, interrupted only by a temporary increase in fertility rates around the mid- $20^{\text {th }}$ century commonly known as the baby boom. The century-long reduction in the average family size coincided with a period of sustained increases in living standards and educational attainment, making the negative association between educational attainment and fertility one of the most established regularities in the social sciences by the 1970s (Cochrane, 1979).

Perceptions of the relationship between education and fertility started to change in the late 1980s after a series of studies suggested that a positive effect of education on the transition to higher-order births was emerging (Hoem and Hoem, 1989; Kravdal, 1992). Although follow-up studies revealed the existence of significant selection effects (Kravdal, 2001; Kreyenfeld, 2002; Kravdal and Rindfuss, 2008), fertility scholars started paying more attention to the changing educational gradient of fertility rates. Since then, a number of studies have shown that the negative effect of educational attainment on fertility outcomes has weakened in a large number of high-income countries (or reversed in the case of men) (De Wachter and Neels, 2011; Kravdal and Rindfuss, 2008; Caltabiano et al., 2009).

The reversal, or weakening of this relationship, has also been substantially documented at the macro level by studies that examined the association between fertility rates and a series of social and economic development indicators, such as the Human Development Index (Myrskylä et al., 2009), female labor force participation (Rindfuss and Brewster, 1996, Ahn and Mira, 2002), and GDP per capita (Luci-Greulich and Thévenon, 2014).

These results are frequently interpreted as the expression of a fundamental change in how education and resources shape the family formation process; i.e., as a return to "more family", which has been made possible by a fairer distribution of unpaid work among better educated couples (EspingAndersen and Billari, 2015). We aim to show, however, that the reversal of the statistical association between educational attainment and fertility does not necessarily imply a reversal of fertility preferences, or of the behavioral mechanisms that underlie this association. Instead, we believe that the narrowing of the educational gradient of fertility is primarily driven by changes in the composition of birth rates. In addition, we argue that, contrary to our current thinking about this relationship, the mechanism that positively connects higher levels of resources and education with fertility outcomes has been present throughout the fertility transition, although eclipsed, for a certain period of time, by the presence of other, more dominant effects.

The key compositional change behind the reversal is related to the transition from a natural to a regulated fertility regime, and the resulting decrease in unplanned births as a share of total observed births. In a nutshell, we argue that as long as unplanned births represent a significant share of total fertility, 
the effect of educational attainment on fertility outcomes tends to be negative, as more information and resources help women and families reduce excess fertility; once fertility becomes fully regulated, however, the positive mechanisms that connect information and resources with fertility outcomes become dominant, and the statistical association reverses.

Our perspective implies that fertility can be understood as the composite expression of two qualitatively different behavioral processes. In the first of these processes, a birth is the result of a decision; i.e., it can be linked to the usual mechanisms represented in models of reproductive decision-making, including utility maximization, social influence, and preferences. In the second of these processes, a birth is the result of an unintentional act, and is thus an event that cannot reasonably be linked to any form of cost-benefit analysis or choice mechanism. As a result, aggregate measures of fertility, such as the TFR, can be seen as composed of two distinct parts: an unintentional fraction, which comprises a progressively smaller share of total fertility as societies develop; and an intentional fraction, which becomes the dominant fraction as the reproductive process becomes increasingly regulated.

Shifting the focus of analysis from total fertility to the gap between desired and observed fertility offers a completely different perspective on the microfoundations of the reversal in the correlation between socioeconomic development and fertility. As Bongaarts (2001) has shown, this gap tends to be negative during the earlier phases of the demographic transition, as achieved fertility exceeds desired fertility; but it turns positive as societies reach the end of the demographic transition and the average number of children moves below the desired number, reflecting a fertility deficit.

As shown in Figure 1, countries with substandard levels of mortality, education, and income per capita tend to have excess fertility, while countries that perform better on these dimensions tend to have fertility deficits. However, in the countries with the highest development indicator values, the gap between observed and average desired fertility tends to be smaller. Although the average gap seems to be smallest in countries that are midway through the development process (with HDI values of around 0.75 ), this is likely an artifact; i.e., the result of heterogeneity in the population and a "double dissatisfaction" scenario, whereby a fraction of the population continues to have more children than they want, while another fraction is already achieving a smaller than desired family size. 


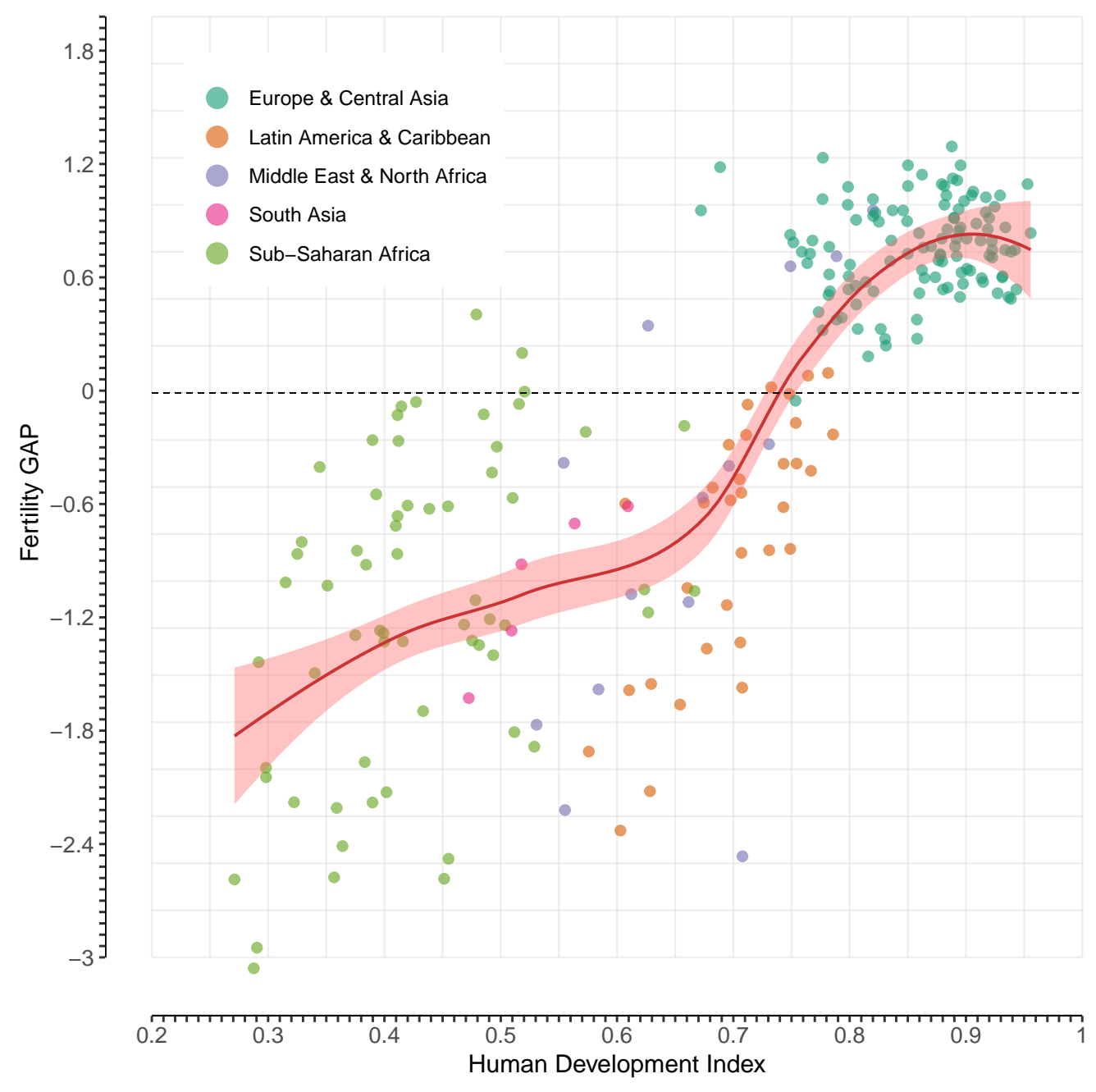

Fig. 1 I Association Between the Human Development Index and the Fertility Gap. The Human Development Index (HDI) is a summary measure of average achievement in three dimensions of human development: length of life, educational attainment, and material living standards. The HDI is the geometric mean of normalized indices for each of the three dimensions. The fertility gap is measured by subtracting the average desired number of children from the observed Total fertility Rate. The information on the desired family size comes from the Demographic and Health Surveys and from (Sobotka and Beaujouan, 2014). The HDI data come from (Myrskylä et al., 2009). Observations correspond to different countries and to different points in time for the same country.

The implication of these results is that, given better information that would allow for the distinction to be made between planned and unplanned fertility, a different relationship will be observed between increased individual ability and these two components of total fertility. This is precisely what the very limited empirical evidence available on this relationship shows. Analyzing a cohort of women born 1957 to 1964 in the United States, (Musick et al., 2009) found that the negative educational gradient 
of completed fertility was largely explained by the significantly higher observed share of unplanned births among less-educated women. A result that resembles Gary Becker's initial findings, as we discuss in more detail in the next section.

In the remainder of this article, we intend to work around the limitations imposed by missing information by applying a simulation approach. More specifically, we use a computational model of reproductive decision-making to simulate a dataset that contains the reproductive histories of several cohorts of women, and that includes an explicit distinction between planned and unplanned births. Then, we model the relationship between education and fertility in our simulated dataset using event-history analysis with the objective of reproducing previously reported regression results. This approach allows us to postulate an explicit data generating process - i.e., a mechanistic model of the weakening educational gradient of fertility - and to show how conclusions can change when we incorporate difficult-to-obtain information into the models that measure the association between educational attainment and fertility over time.

\section{Increased Resources and Fertility: Theory}

Because educational attainment measures are usually easier to obtain than reliable estimates of income or wealth, they are widely used in empirical studies as a way of classifying individuals according to their resources and ability. Thus, the discussion surrounding the relationship between education and fertility tends to overlap with the discussion surrounding the relationship between income and fertility.

One of the reasons why these relationships have received so much attention is the observed long-run negative association between increased resources and fertility outcomes. From a theoretical point of view, this is an unexpected, somewhat puzzling observation that challenges most established analytical frameworks in the social sciences, from evolutionary anthropology to economics. In all of these frameworks, first principles indicate that increased access to resources should result in a larger number of offspring.

Over time, this inability to ground the observed relationship on a well-established theoretical basis, led to the formulation of a number of ad hoc hypotheses. Two of the most influential ideas in our current understanding of this problem come from neoclassical economic models: namely, the idea of opportunity costs, and the idea of a quantity-quality trade-off (Becker and Lewis, 1973, Becker and Tomes, 1976).

The popularity of these concepts lies in their perceived ability to explain the observed negative association between increased access to resources and fertility. However, a closer look shows that neither the opportunity costs mechanism nor the quality of children mechanism are enough to generate this nega- 
tive relationship (Jones et al., 2008). Within a neoclassical framework, a decrease in fertility cannot be produced in the context of increasing resources unless additional restrictive assumptions are included in the models: namely, that the time needed to raise a child is exclusively incurred by the parents (no outsourcing); and, more importantly, that the preferences of individuals differ along income lines. As Galor (2011) put it: " [The theory] hinges on the supposition that individual's preferences reflect an innate bias against child quantity beyond a certain level of income».

Indeed, the assumption that less advantaged individuals have a stronger preference for children has been repeatedly disproved by research on long-term fertility intentions (Berrington and Pattaro, 2014; De Wachter and Neels, 2011; Testa, 2014). But the shortcomings of neoclassical economic models in capturing the dynamics of human reproduction are not restricted to this particular issue. The rational choice theory these models rest upon requires a series of assumptions - namely, utility maximization, complete preferences, perfect information, and, crucially, the assumption of perfect control over the reproductive process - that are incompatible with a process that, for many contexts and time periods, can be described as being largely unintentional.

Interestingly, Gary Becker's first approach to addressing this issue avoided these pitfalls (Becker, 1960). In his original study, the negative relationship between income and fertility was not presented as the outcome of a trade-off between the quantity and the quality of children, but, rather, as resulting from the omission of a key variable: knowledge about contraception. To test this idea, Becker analyzed the relationship between income and fertility by separating couples according to whether or not they had planned their children, and indeed found a positive relationship between economic status and desired fertility.

An increase in income or a decline in the cost of children would affect both the quantity and quality of children, usually increasing both. An increase in contraceptive knowledge would also affect both but would increase quality while decreasing quantity. [...] Differential knowledge of contraception does convert a positive relation between income and desired fertility into a negative relation between income and actual fertility Becker (1960)(italics in the original).

Unfortunately, this initial interpretation was overshadowed by the attention given to the more theoretically appealing quantity/quality distinction (Doepke, 2015). Later revisions of the theory introduced the notion of a trade-off between quantity and quality, which implied that a negative relationship between income and fertility could be generated without considering differential contraceptive knowledge and the difficulties associated with measuring unplanned fertility (Becker and Lewis, 1973; Becker and Tomes, 1976). 


\section{Unplanned Fertility}

Although analyses of the first demographic transition paid considerable attention to fertility control, especially those that looked at the supply side (Easterlin and Crimmins, 1985); the discussion of fertility trends in the post-war era was completely dominated by social and economic arguments. In the report of the IUSSP meeting in 1981 on low fertility in Europe, (Wulf, 1982) noted: "The practice of contraception [..] is barely mentioned in the course of the population policy debate currently being waged in Europe".

In one notable exception, Murphy (1993) showed that the use of the contraceptive pill played a key role in the fertility decline of the 1960s and 1970s in Britain. However, the overwhelming majority of demographic analyses of unplanned fertility have focused on developing countries (Bongaarts, 1997, 2003, 1990), and to some extent on the US, where high unplanned pregnancy rates among lesseducated young women have long been a pressing public health concern (Henshaw, 1998; Boonstra et al., 2006; Finer and Henshaw, 2006). The scarcity of data on unplanned pregnancies and births in Europe is likely due to a combination of difficulties in measuring the unintended fraction of births and the belief that the control over the reproductive process is nearly perfect, or is at least moving in that direction (Klijzing, 2000).

The few available estimates of unplanned fertility, however, contradict these assumptions. For example, half of the decline in fertility in the 1970s in France has been attributed to the drop in unplanned births (Régnier-Loilier et al. 2007). Moreover, it has been estimated that $25 \%$ of the births to women born around 1950 in Italy were unplanned (Castiglioni et al., 2001). If we consider that these cohorts reached their peak reproductive years during the 1970s and 1980s, and thus after the diffusion of effective contraceptive methods, it seems reasonable to assume that a large fraction of births to women of earlier cohorts were unplanned.

\section{Education and Fertility: Empirical Approaches}

As mentioned above, efforts to identify a positive association between educational attainment and fertility outcomes date back to the 1980s. The typical approach to addressing this question relies on the estimation of educational gradients across cohorts using hazard regression models for the transition to the second and the third birth. For example, a study using Swedish data found higher relative risks of transitioning to a second or a third birth for women with higher education, when their age at first birth and employment status were controlled for (Hoem and Hoem, 1989); while another study reported a positive relationship between education and third birth rates for married Norwegian women (Kravdal, 1992). 
While these findings of a positive relationship between women's educational attainment levels and fertility outcomes were unprecedented, they were theoretically plausible in the Scandinavian context, where full-time day care, job protection for mothers, and the relatively high levels of involvement of fathers in housework supported the compatibility of family and employment. But when similar results were repeatedly found for West Germany as well (Huinink, 1989, 1995, 2001 in Kreyenfeld (2002), it became clear that a closer examination of this relationship was needed.

Indeed, the positive effect of education on the transition to higher-order parities turned negative when the transitions to different parities were modeled jointly, and a parameter to capture unobserved heterogeneity was included in the regression models (Kravdal, 1992; Kreyenfeld, 2002). These models were designed to control for heterogeneity in family formation preferences (family proneness) that can lead to biased estimates when women who had a previous child at the same age, but belong to different educational groups, are compared.

Revisiting the problem years later, Kravdal and Rindfuss (2008) showed that the negative effect of education on higher-order births disappeared for recent cohorts of women in Norway, even after controlling for selection effects. Until today, this study remains one of the central references in the literature. Thus, we take it as a reference point in developing our argument. In Figure 2, we present coefficients from hazard regression models of the risk of having a second birth by educational attainment and cohort, as reported in this study. 
Fig. 2 | Hazard Ratios of Transitioning to a Second Child by Cohort and Educational Level, with the Lowest Educational Level as the Reference as Reported in Kravdal and Rindfuss (2008) I Women, Norway.

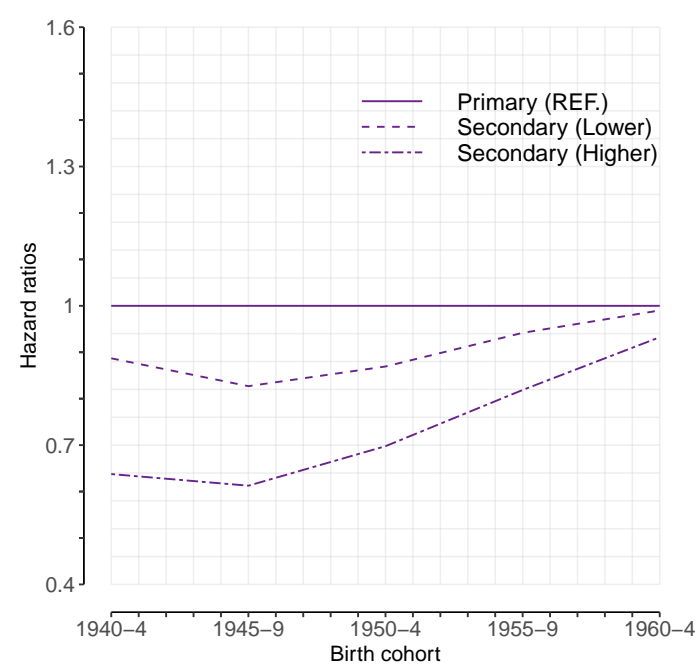

(a) Secondary Education

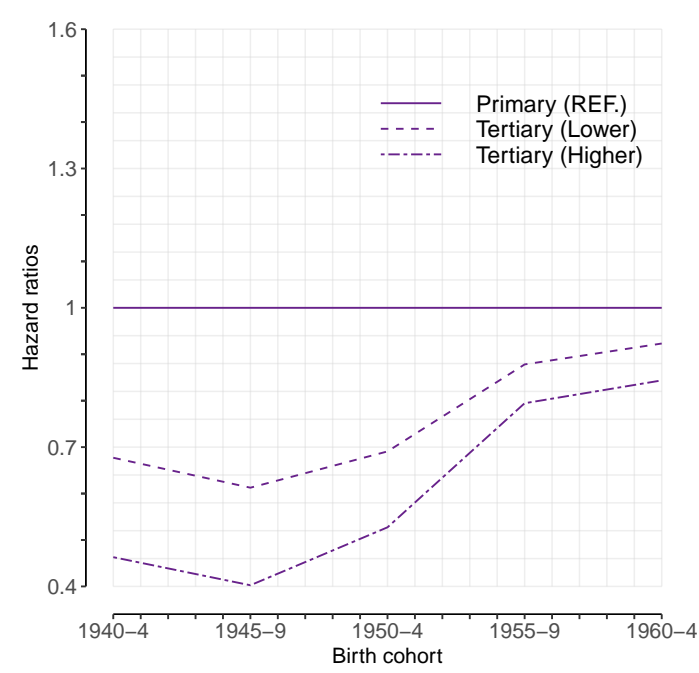

(b) Tertiary Education

Both panels show a convergence among educational groups; i.e., a reduction of the negative effect of education for women with higher education as their relative risk approaches the risk of the group of women with less education (approaches one in the y axis).

In the following sections, we intend to show how these results can be replicated using simulated data generated by a known data-generating process; or, in other words, how a model with a well-defined set of social and behavioral mechanisms can produce data that resemble the data displayed in Figure 2. However, before proceeding, we provide a description of our simulation model, and of the statistical models applied to our simulated data in order to replicate the results introduced in this section.

\section{Simulation Model}

We use a discrete-event simulation that generates synthetic reproductive trajectories for the cohorts of women born between 1940 and 2018 in Norway. These trajectories start with the formation of a cohabiting union. After a union is formed, the partners agree on a desired family size, which they will actively try to achieve before the female partner reaches age 50 or dies. Every 12 months, the partners have to decide whether or not to have a child in the next year; a decision that depends on the time elapsed since the last birth (if any), the labor market participation status of the female partner, and 
her educational level (which are assigned from the empirical distributions shown in Figure 3). After they make the decision, the probability of actually having a birth depends on the risk of conception for non-contracepting women of a given age, known as fecundability. But even if the partners decide not to have a child, they are still subject to the risk of experiencing an unplanned pregnancy.

Fig. 3 I Proportion of Women by Education Level (a) and Labor Force Participation by Education (b) I Cohorts, Norway. Although the model classifies the simulated women as inactive/active in the labor market; here, for the sake of clarity, only the proportion of women actively participating in the labor market is displayed in Figure $3 b$. As the data clearly shows, the experiences of women of different educational levels with respect to paid work have become more similar, while the proportion of women who attained tertiary education has increased steadily over time. See Appendix A for more information on these data.

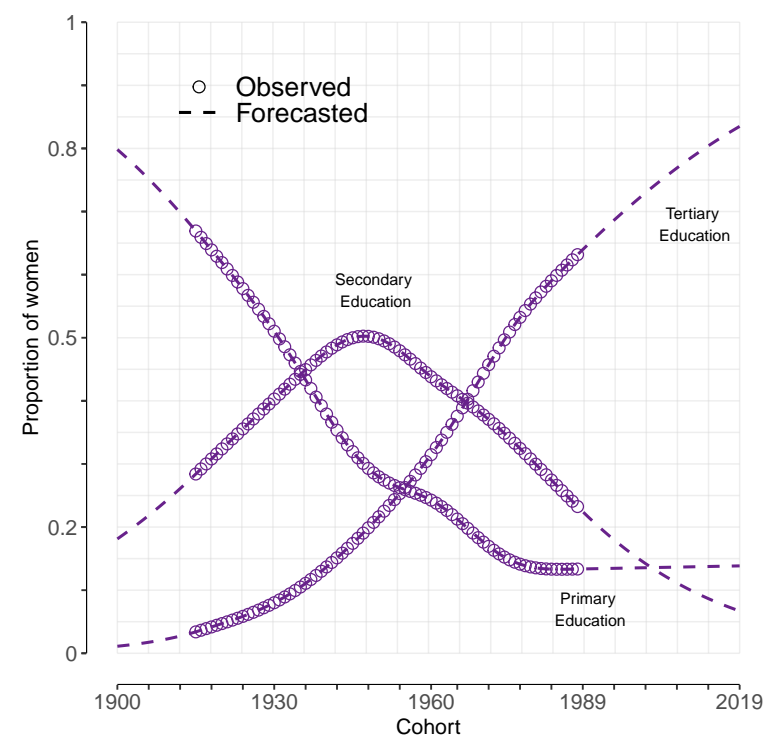

(a) Educational Attainment

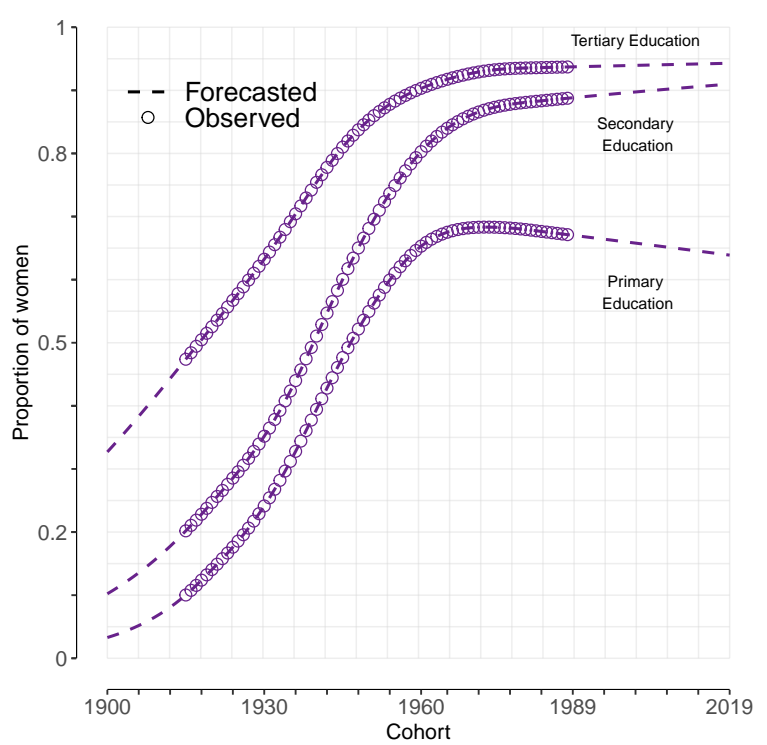

(b) Labor force Participation by Educational Attainment

One important assumption the model makes is that participating in the labor market imposes a penalty on the intention to have a child, given the time constraints and the competing interests that most working women face when they consider becoming a parent. But we also let educational attainment alleviate this penalty as a means of incorporating a number of mechanisms that positively connect access to higher education and resources to fertility decisions. These mechanisms include, among others, the increased ability to outsource childcare and housework or to negotiate a fairer division of unpaid work within the household; more flexible working hours; and having fewer difficulties reentering the labor market after spells of inactivity.

The model then allows for fertility outcomes to be positively associated with the educational level of an 
individual, but it also incorporates three other mechanisms through which a higher level of education implies a reduction in the number of children achieved at the end of a woman's reproductive life. First, we assume that dual-earner households tend to want a smaller number of children than households with a male-breadwinner arrangement. Given that more educated women have higher levels of labor market participation, that assumption implies a negative association between educational attainment and desired family size. Second, following the literature on the adoption of effective contraceptive methods, we allow the risk of an unplanned birth to be reduced for more educated women, which implies a negative correlation between educational attainment and excess fertility. Finally, given that most people wait until they have finished their education to start a family, we make the formation of a cohabiting union dependent on the number of years spent in formal training. This implies a reduction in the length of time women are exposed to the risk of a pregnancy, which will, in most cases, translate into a smaller achieved family size.

As we explained above, our hypothesis is that the change in the weight of the negative versus the positive effects of education on fertility can explain the reduction in the negative educational gradient of fertility outcomes over time.

In the next section, we introduce the basic operation of the model through an example. A more detailed technical description can be found in Appendix B. The model is implemented in $\mathrm{R}$ (R Core Team, 2015), and its estimation requires access to a distributed computing infrastructure. All of the code and the data necessary to reproduce the results presented in the paper can be found here.

\subsection{Example Trajectory}

Figure 4 depicts a simulated reproductive trajectory of a woman born in 1940. Whenever a new woman is born in the simulation, she is assigned an educational level (primary, secondary, or tertiary) and a labor force participation status (participating/not participating) from the empirical cohort distributions presented in Figure 3). Let us assume the woman in our example only completes primary school, and that she works. 
Fig. 4 | A Simulated Reproductive Trajectory

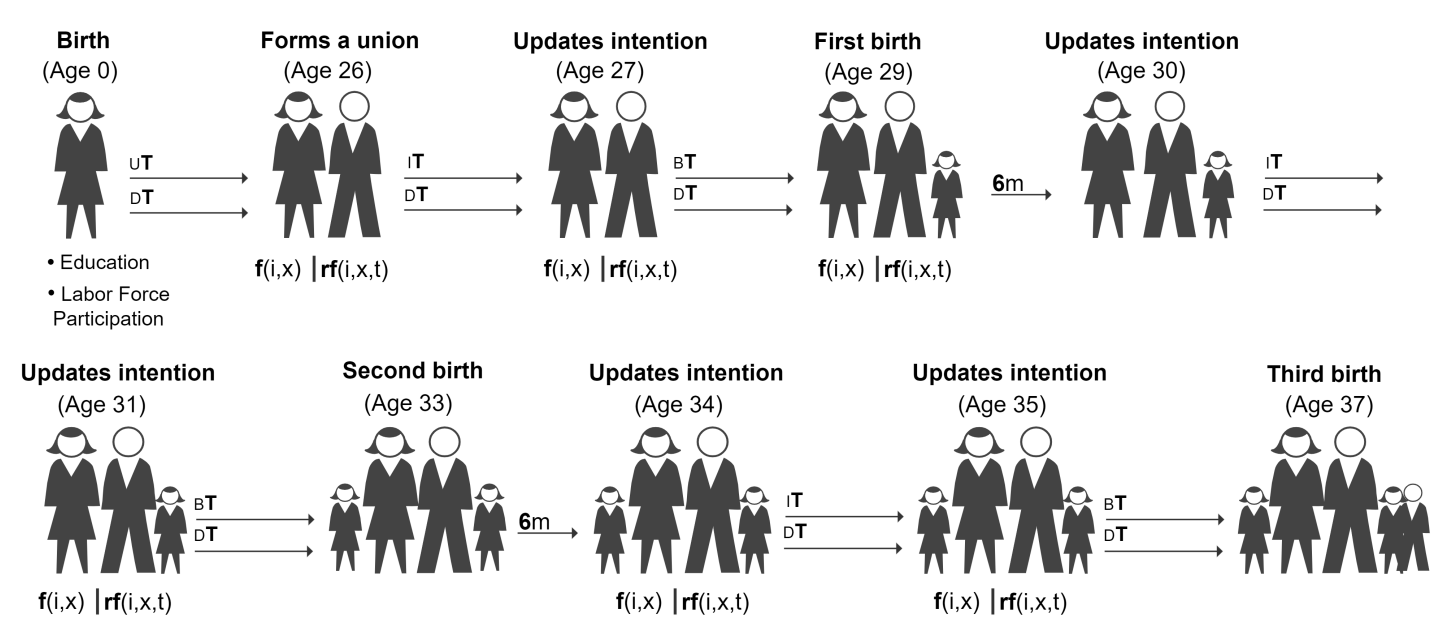

At this point, the model also produces two waiting times: the waiting time until the formation of a union $\left.{ }_{U} T\right)$ and the waiting time until death $\left.{ }_{D} T\right)$. These events compete with each other, meaning that the event with the shortest waiting time is realized. The event that comes first in our example is the formation of a cohabiting union. The age at which the woman in our example forms a union (26) is influenced by the length of time she spends in the educational system, which depends on her educational level.

At union formation, the newly formed couple decide how many children they will try to have; i.e., they define their desired family size $D$, which will remain fixed throughout the couple's reproductive trajectory. In defining their desired family size, this couple will take into account not only the existing social norm regarding the ideal number of children, but also whether both members of the couple work outside the home. Note that although only women are simulated, the presence of an employed partner is assumed for those women who form a union. This implies that after a union is formed, the couple, instead of the woman, can be seen as the "agent" in the model.

Going back to our example, given that our hypothetical woman works, the couple will tend to prefer a family size that is smaller than the existing norm. Although the prevailing ideal at the time (calendar year 1966) is having three children, they decide to have two.

Upon union formation, the partners have to decide whether they will try to conceive a child in the next year. In case they decide to have a child their probability of succeeding will be determined by her fecundability $f(i, x)$. The couple in our example decide not to have a child in their first year of cohabitation, which implies that they also have to avoid an unplanned conception. In this case, their probability of failing is determined by her residual fecundability $\operatorname{rf}(\mathrm{i}, \mathrm{x}, \mathrm{t})$. 
In our example, they manage to avoid an unplanned pregnancy during their first year of marriage. Now the waiting time until death competes with the waiting time until the moment at which the couple will update their intention and make a new decision ${ }_{I} T, 12$ months later. At the end of this 12-month period, the partners decide to try to have a child. When they succeed in conceiving, a waiting time until birth ${ }_{B} T$ is generated. This results in a first birth when our hypothetical woman is 29 years old. The occurrence of this birth temporarily depresses her intention to have another child.

After the partners return to being exposed to the risk of a conception, they decide not to have another child in the first and the second year after the first birth. However, in the second year, they fail to prevent an unplanned conception, which results in the woman having a second child when she is 33 years old. When the woman is 37 years old, she has a third child who is unplanned but also unwanted, as the couple had already achieved their desired family size of two children.

\subsection{Estimation}

After we set up our model, the objective is to find the combination, or distribution of combinations, of parameter values that can provide a better fit to the available data in Norway. We do so by relying on a likelihood-free estimation approach, which, as it name indicates, allows for inference and uncertainty quantification in a context in which obtaining an analytical expression of the likelihood is not possible, but it is possible to simulate the model output at different combinations of parameter values. In particular, we use an Approximate Bayesian Computation (ABC) algorithm (see: Beaumont, 2010, 2019). The typical ABC algorithm proceeds by simulating realizations of a model's outcome from different parameter values, and by retaining those values that produce outcomes that are "close" to the observed data, according to a predefined metric of distance.

The specific approach we apply here was proposed by (Gutmann and Corander, 2016), and uses Bayesian Optimization to perform an efficient, sequential search of the parameter space. This approach was developed to reduce computation time when - as is the case for our model - simulating model output is time-consuming, and it does so by focusing on the region of the parameter space where the distance between simulated and observed data tends to be small.

In more formal terms, let $\mathcal{X} \subset \mathbb{R}^{d}$ be the parameter space, where $d$ is the number of parameters. At a given combination of parameter values $\theta \in \mathcal{X}$, we compute $\Delta_{\theta}$ the Mean Squared Error (MSE) at this location as a weighted mean of the MSEs for two vectors:

- Age-specific fertility rates between ages 14 and 50 for the 1960-2016 period. Available from the Human Fertility Database (2011).

- Cohort completed fertility by education. Obtained from (Zeman et al., 2014). 
The objective of the estimation procedure is to find the region of the parameter space where the distance $\Delta_{\theta}$ is smaller. The basic idea is to proceed sequentially, taking a sample of $k$ locations $\theta_{1}, \ldots, \theta_{k}$ from $\mathcal{X}$ and computing $\Delta_{\theta_{1}}, \ldots, \Delta_{\theta_{k}}$. This evidence is then used to decide where to search next in the parameter space. The distance $\Delta_{\theta}$ is then computed on a new set of locations to be explored. To avoid having to compute the model at each of these new points, at this stage the model is substituted by an emulator; i.e., a model of the functional relationship between the model parameters and the distance. Specifically, we fit a Gaussian process regression using the mlegp R package (Dancik and Dorman, 2008).

The emulator provides predictions of the distance at any combination of parameters, and the decision of where to search next is made using a specific selection criterion. Following (Gutmann and Corander, 2016) we use a lower confidence bound criterion, which balances exploitation, selecting the locations with the best expected values; and exploration, selecting locations where the uncertainty is higher.

The basic operations of the procedure are presented in the following pseudo-code:

Obtain an initial sample of $\mathcal{X}$ of size $n_{0}, \theta_{1}, \ldots, \theta_{n_{0}}$

Compute $\Delta_{\theta_{1}}, \ldots, \Delta_{\theta_{n_{0}}}$

Set $n=n_{0}$

While $n \leq N$ do

Map the relationship $\theta \rightarrow \Delta_{\theta}$ with a Gaussian Process emulator $G(\cdot)$

Obtain a new sample of $\mathcal{X}$ of size $n^{*}$

Obtain predictions for $G\left(\theta_{k}\right) \quad k=1, \ldots, n^{*}$

Compute acquisition function $A(\cdot)$

Obtain the new locations to be explored $\theta_{j}$

Compute $\Delta_{\theta_{j}}$

Increment $n$

end While

Return:

The value of $\theta$ that minimizes $\Delta_{\theta}$; or

A fraction $p$ of $\theta$ values with lowest $\Delta_{\theta}$ 


\section{Hazard Regression Models}

Using the procedure described in the preceding section, we find the combination of parameter values that produce the simulated reproductive trajectories that most closely resemble the observed trajectories of Norwegian women in the cohorts of interest. Estimated parameter values are presented in Appendix B. With these values as input, we produce a new simulation with a larger number of trajectories. Using the information on the age of the mother at each birth and her educational attainment level, we build a simulated dataset that is identical in structure to the one used by Kravdal and Rindfuss (2008). This information alone is sufficient to answer the question of whether our proposed datagenerating mechanism can reproduce the observed convergence in the risks of higher order parities for women with different educational attainment in Norway. But our simulated data allows us to go a step further and explore the relationship between education and desired fertility, i.e. how education affects the risk of an additional planned birth. An analysis that is similar in concept to the originally proposed by Becker in his 1960 article (see Section 2).

In order to obtain estimates comparable to those presented in Kravdal and Rindfuss (2008), we model the hazard of transitioning to higher-order parities in our simulated data using a discrete-time hazard regression approach with Complementary Log-Log link function. We also follow their approach by estimating separate models for each transition (i.e., the second and the third birth) and for each fiveyear birth cohort; and by modeling the baseline duration using linear splines, with one knot at age 35 in the case of age, and four knots at two, four, six, and eight years in the case of time since previous birth. To explore the relationship between educational attainment and desired fertility, we only consider planned births; i.e., we remove those births that occurred after the couple in the simulation had reached their desired family size. As we argued earlier, removing unplanned fertility should result in estimates that reflect a neutral-to-positive association between educational attainment and the risk of having a second or a third birth.

\section{Results}

We start this section by presenting the fit of our model to a number of indicators that summarize the dynamics of Norwegian fertility over time. Figure 5 shows simulated vs observed Age-Specific Fertility Rates (ASFR) in Norway, for selected years from 1970 to the present. The model reproduces the long-term, post-baby boom decline in birth rates in Norway, but also the substantial postponement of fertility registered during this period, expressed here as a move down and a shift to the right of the distribution of the ASFR. 
Fig. 5 I Observed vs. Simulated Age-Specific Fertility Rates, Selected Years, Norway. The parameter values associated with the simulated results presented in this figure can be found in Appendix B.

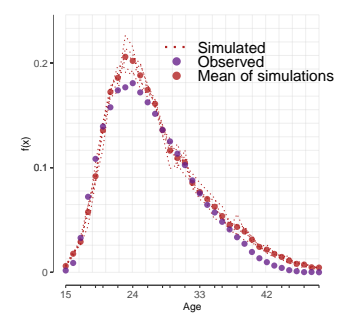

(a) 1970

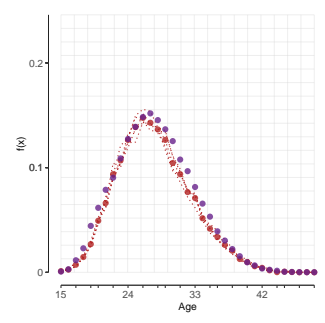

(b) 1990

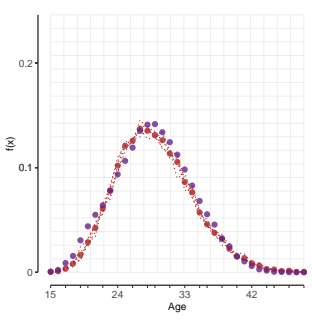

(c) 2000

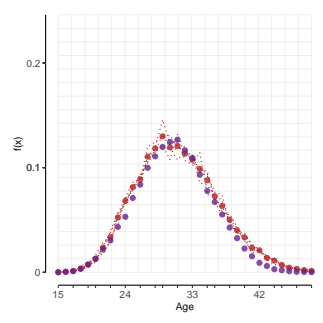

(d) 2018

Figure 6 shows that the model also closely reproduces several key dimensions of the observed fertility dynamics in Norway since the second half of the $20^{\text {th }}$ century, as expressed by the evolution of Completed Cohort Fertility (6a), Completed Cohort Fertility by education (6b), and the Mean Age at Birth 6c). These results indicate that the trajectories generated by the model resemble those of real Norwegian women in the period along multiple dimensions, namely, the number of children each woman ever had at the end of her reproductive life; the timing of those births; and, importantly, the differences observed between women with different educational attainment levels. 
Fig. 6 I Model Fit. Selected Fertility Indicators, Norway. We run five iterations at the same combination of parameters to capture the inherent stochasticity of the model. The dotted red lines represent each of these runs, while the red dots represent their average. The grey dots represent the observed values.

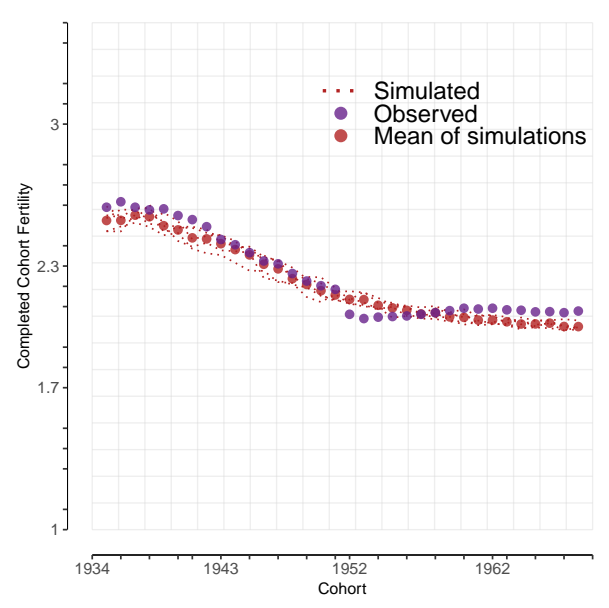

(a) Cohort Completed Fertility

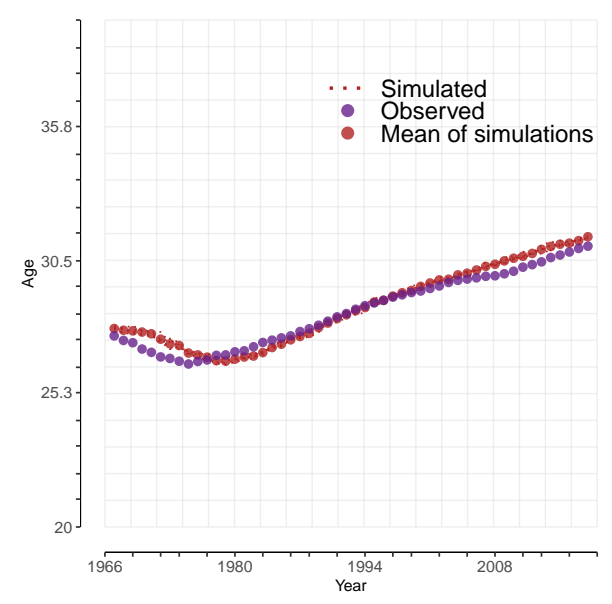

(c) Mean Age At Birth

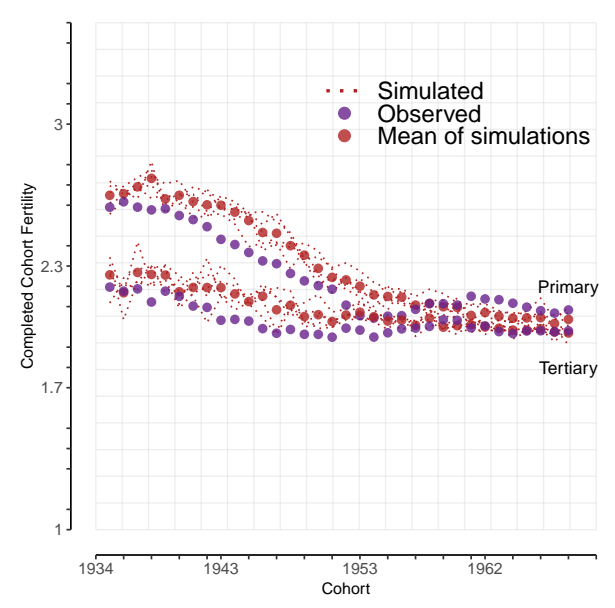

(b) Cohort Completed fertility by Education

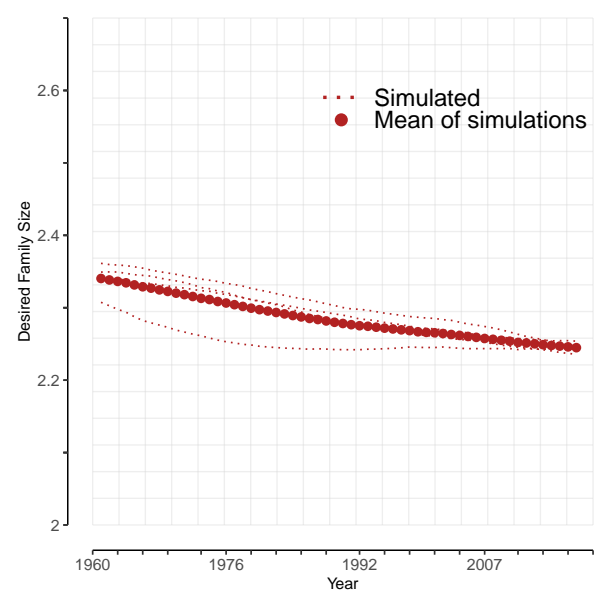

(d) Mean Desired Family Size

Indeed, Figure $6 \mathrm{~b}$ shows that the simulated data reproduce the observed convergence in achieved family size among women with different educational attainment levels. In the simulated population, this trend is mostly driven by faster declines in the share of unplanned births among women with less education. It is important to note as well that this convergence is observed in the context of a sustained decline in family size preferences across educational levels $6 \mathrm{~d}$. 
The evolution of the mean age at birth shows that the potential gains in general fertility levels of a more resourceful population who are increasingly capable of achieving their fertility goals can be counterbalanced by further reductions in the time available to form a family as education continues to expand.

Moving to the micro level, we try now to answer our original question of whether the data-generating process implied by the model is able to reproduce the observed trends in the risk of transitioning to higher-order parities across cohorts in Norway. Figure 7 compares hazard ratios estimates for the transition to a second and a third child obtained from the simulated data with those reported in Kravdal and Rindfuss (2008) using the same modeling approach. The trend described by the simulated data follows the observed trend showing that the risk of a second birth (Figures 7a \& 7b) and a third birth (Figures $7 \mathrm{c} \& 7 \mathrm{~d}$ ) for women with secondary and tertiary education becomes more similar over time to the risk experienced by women with primary education only. 
Fig. 7 I Hazard Ratios for the Transition to Second Child by Cohort and Educational Level, with the Lowest Educational Level as the Reference I Women, Simulated vs. Observed Results. To keep Given that the focus of the analysis are the changes over time, the simulation model does not distinguish between different levels of secondary or tertiary education. Simulated results are reported with $95 \%$ confidence intervals. The uncertainty of the estimates computed on the observed data is not reported in (Kravdal and Rindfuss, 2008). See Appendix A for additional details on the educational attainment data. A more detailed description on the hazard regression models, including the coefficients presented here, can be found in Appendix $\mathrm{C}$.

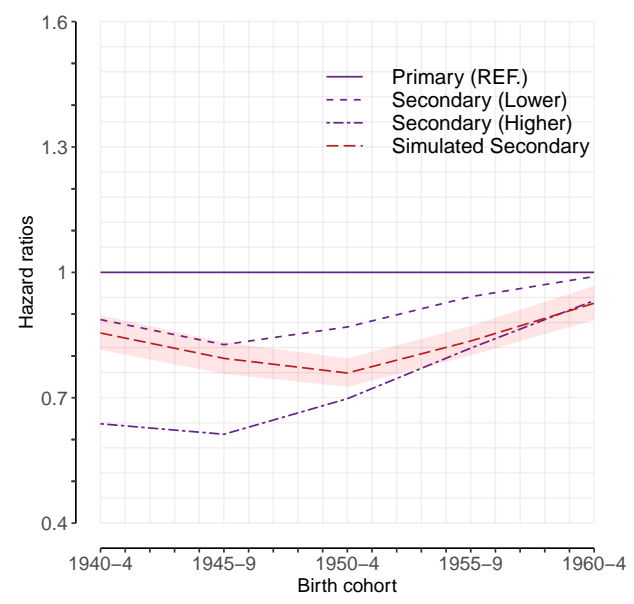

(a) $2^{\text {nd }}$ Birth - Secondary Education

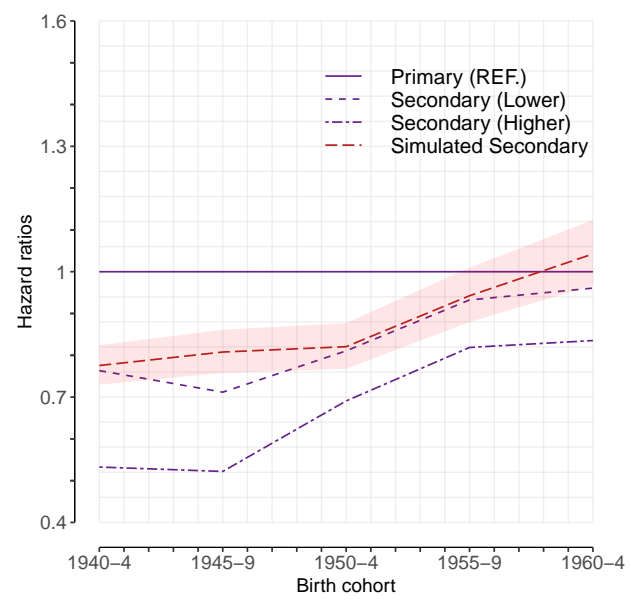

(c) $3^{\text {rd }}$ Birth - Secondary Education

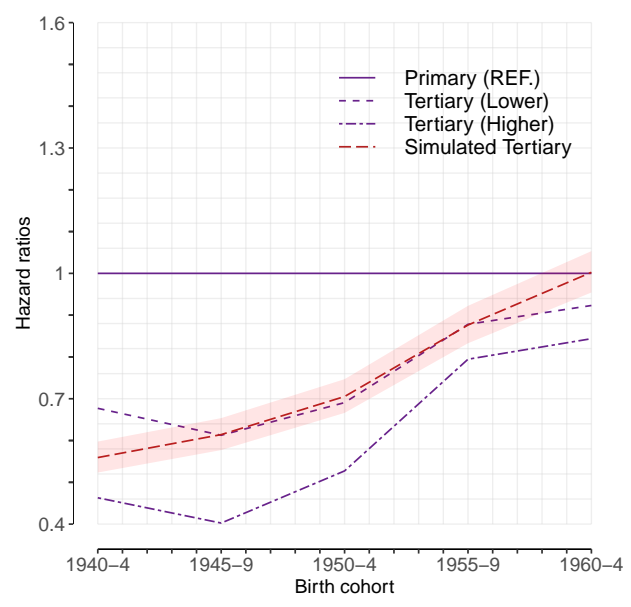

(b) $2^{\text {nd }}$ Birth - Tertiary Education

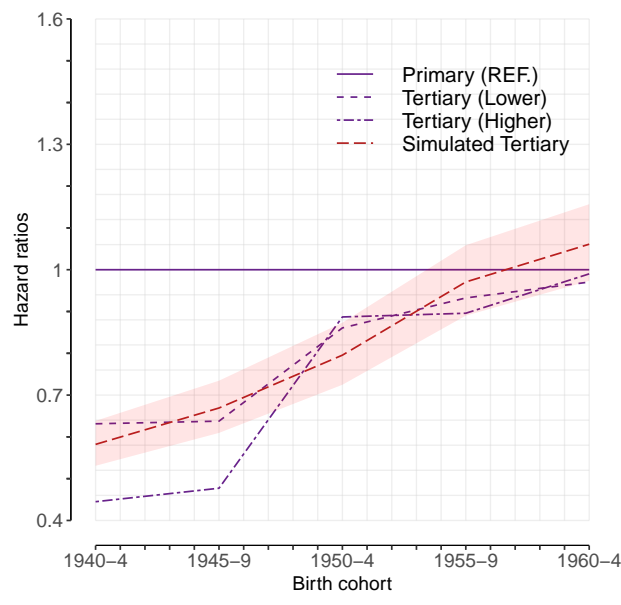

(d) $3^{\text {rd }}$ Birth - Tertiary Education

We now focus exclusively on the simulated data, and compare the results from the original model with those obtained when the outcome considered is desired fertility instead of total fertility (see Section6). 
As can be observed in Figure 8, when unplanned births are excluded, the educational gradient in the risk of transitioning to a third birth disappears. As discussed earlier, the results obtained from the simulated data showed the same pattern of convergence as the results obtained from the observed data, with the educational gradient of total fertility disappearing over time. In the case of the transition to a third birth, more specifically, the gradient disappears for the two more recent cohorts. However, when the same hazard regression models are applied to simulated data that considers only planned births, the gradient disappears also for the earlier cohorts.

Fig. 8 I Hazard Ratios for the Transition to a Third Birth by Cohort I Comparison of Model Specifications.

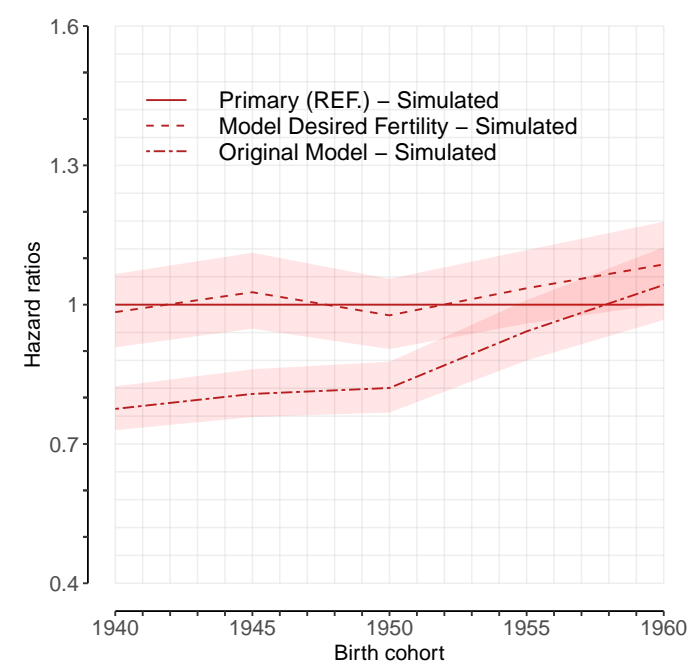

(a) $3^{\text {rd }}$ Birth - Secondary Education

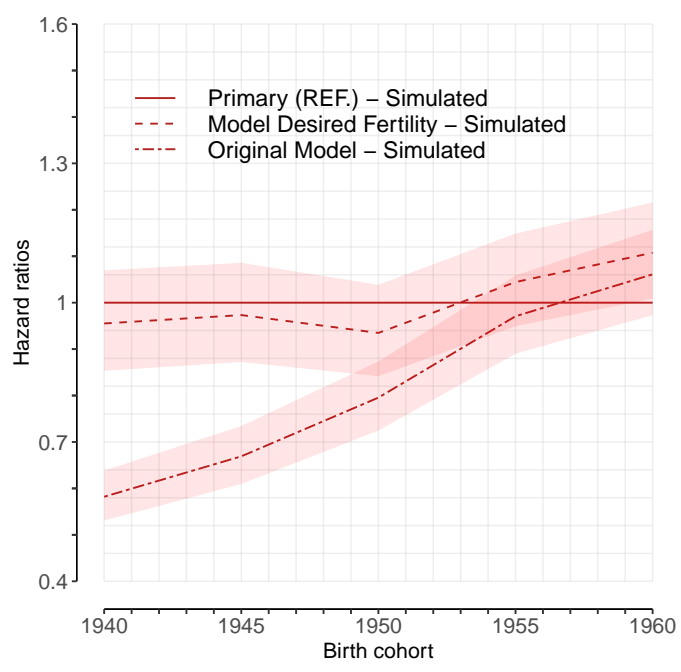

(b) $3^{\text {rd }}$ Birth - Tertiary Education

\section{Discussion}

The recently observed reversal of the negative correlation between development and fertility allowed to realign theory and evidence, resolving a long-standing paradox in the human sciences from a firstprinciples perspective. But at the same time, it has challenged a number of ad hoc hypotheses that were put forward over the years to explain why privileged access to information and resources was associated with reduced family sizes.

In this article, we argued that throughout the fertility transition, our understanding of the relationship between ability and fertility has been confounded by the omission of one key variable: the ability to regulate the reproductive process. While early economic approaches recognized that the distinc- 
tion between planned and unplanned fertility was critical, this idea was later sacrificed to protect the integrity of the models that came to dominate the field. Although demographers tend to pay more attention to this distinction, data limitations very often prevent its incorporation in statistical analyzes. Human fertility provides a perfect example of how an identical outcome - in this case, a birth could emerge from completely different underlying behavioral processes, which therefore need to be modeled accordingly. As a planned/wanted birth is the result of a goal-seeking behavior, the risk of experiencing such a birth should be positively associated with the additional ability provided by a privileged access to resources. Conversely, as an unplanned birth results from the inability to control the reproductive process, experiencing such an event should be negatively associated with the skills acquired through formal schooling, and with the individual and family resources that usually contribute to the achievement of higher educational levels.

Starting with this simple premise, we set out to show that the disappearing educational gradient of fertility at the micro level, and the corresponding reversal of the relationship between development and fertility at the macro level, can be understood as an expression of the declining share of unplanned births across cohorts. In other words, the diffusion of effective contraceptive methods has made women's life courses more similar with respect to the number of unplanned births they experience throughout their reproductive lives. As populations move from a natural to a regulated fertility regime, the fertility-reducing effects of education and access to resources become less dominant, and the role of these characteristics in the ability to fulfill fertility preferences becomes more evident.

We tested this hypothesis by implementing the abovementioned dynamics in a simulation model, and showed that the data-generating mechanism implied by the model can reproduce the disappearing educational gradient of fertility across cohorts. We also showed that when only desired fertility is considered, the educational gradient completely disappears.

Although the reversal of the statistical association between education and fertility is usually interpreted as resulting from changes in preferences, our findings suggest that this reversal can be observed in the absence of a parallel reversal at the level of individual behavior, and in the presence of a continuous decline in family size preferences across socioeconomic strata.

These results offer important insights into potential future fertility scenarios, as our findings indicate that in many countries, the continued expansion of education and access to resources could provide a respite from the sustained decline of fertility rates, provided the reduction in exposure implied by the postponement of the transition to parenthood does not offset the fertility gains associated with further economic development. 


\section{A Appendix}

\section{A.1 Data}

Administrative register data covering the entire resident population of Norway were used to calculate completed cohort fertility by education and to create annual tables on the highest level of education attained and labor force participation by birth cohorts. In line with (Kravdal and Rindfuss, 2008, p. 858), we excluded individuals not born in Norway. The population register of Norway contains a unique ID for every resident, which makes it possible to link information from different registers.

Cohort completed fertility at age 40 was computed from a dataset that provides links between all registered individuals and their children. Next, annual data displaying the resident population at the beginning of each year were linked to information from the National Database on Education to obtain the highest level of education attained by women in the birth cohorts analyzed. We considered three levels of education corresponding to International Standard Classification of Education (ISCED) levels 1-2, ISCED 3-4 and ISCED 5-6.

As similar approach was used to calculate the proportion of women (aged 30 to 55) in the labor market by highest level of education and cohort. Here we had access to data from the Income and Tax Register and Statistics Norway's Event History Database for the years 1967 to 2014. We extracted information on the annual income obtained through employment or self-employment. If the annual income obtained through employment and/or self-employment was twice the annual basic amount in the National Insurance Scheme (See: The Norwegian Tax Administration), individuals were defined as active, otherwise as inactive. The basic amount is used as a basis for calculation of pensions and other social benefits.

\section{B Appendix}

\section{B.1 Desired Family Size}

As the example presented in Section 5.1 clearly shows, decisions are important drivers of the reproductive outcomes in our model. We distinguish between two types of decisions: how many children to have (long-term desired family size), and when to have them (short-term intentions).

The desired family size $D_{i}$ of woman $i$ in the simulation is formed immediately after a union is established, and is derived from a Gamma distribution (see below). The choice of Gamma is based on the fact that the distribution of family size preferences is positively skewed, with the mode in the 1-3 range, depending on the country and the period; and a right tail formed by a decreasing number of responses associated with larger family sizes (based on analyses of data from the Integrated Value 
Surveys program).

Based on the assumption that couples in which both partners work will tend to prefer a smaller family, we make the desired family size dependent on the labor force participation (active/inactive) of the woman. Our model for $D_{i}$ also takes into account the fact that individuals live in a society with a given set of norms, and that these social norms influence their preferences as much as their individual characteristics.

In practice, the desired family size $D_{i}$ of couple $i$ in the model is obtained by rounding to the nearest integer a number drawn from a truncated Gamma distribution with expected value:

$$
E_{G}=\bar{D}_{t[i]} \cdot\left(1+(-1)^{w_{i}} \cdot\left(1-p_{t[i]}\right) \cdot \delta\right)
$$

where $t[i]$ is the time at union formation for woman $i$, and $\bar{D}_{t[i]}$ is the average desired family size for all women of reproductive age at time $t[i]$.

$\bar{D}_{t[i]}$ represents the existing social norm regarding the ideal family size at a given time. The amount by which $E_{G}$ departs from this norm is given by $(-1)^{w_{i}} \cdot\left(1-p_{t[i]}\right) \cdot \delta$, where $w_{i}$ is a dummy variable that indicates the labor force status of woman $i(0=$ inactive, $1=$ active $), p_{t[i]}$ is the proportion of women in the population who share her labor force participation status, and $\delta$ is therefore the maximum proportional departure from the norm. The implication of the $\left(1-p_{t[i]}\right)$ term is that the larger the fraction of the population who share her labor force participation status is, the closer to the existing social norm the woman will be. For instance, in the extreme case of a homogeneous population of inactive women, the deviation from the norm is zero if newly-cohabiting woman $i$ is inactive and is equal to $\delta$ if she is active.

By considering the deviation from existing family size norms, the proposed model represents the evolution of preferences as a path dependent process, a dependency that results from a feedback loop between the behavior of previous cohorts, expressed as an aggregate-level societal norm, and the decisions taken at the micro-levels by individuals in subsequent cohorts.

\section{B.2 Intentions}

While the desired family size $D_{i}$ determines the attempted final parity, we define an intention $I_{i, t}$, which plays a role in determining the timing and the likelihood of each specific birth. More specifically, the intention $I_{i, t}$ is the probability that a couple will decide to try to have a child in the next year. The strength of the intention depends not only on individual, fixed characteristics, but also on the time elapsed since the previous birth. 
For a couple who have achieved their desired family size, $I_{i, t}=0$. Otherwise, the intention is given by:

$$
I_{i, t}=\left(\beta_{i}-\omega_{i} \cdot w_{i}\right)\left(1-e^{-\lambda \cdot d_{i, t}}\right)
$$

where $\beta_{i}$ is a baseline that represents the probability of deciding to have a child in a given year for a non-working woman who has not had a child recently and has not yet achieved her desired family size.

For working women, the intention also depends on education through $\omega_{i}$, which we define as:

$$
\omega_{i}=\frac{\eta}{1+\exp \left(\epsilon \cdot\left(y_{i}-\tau\right)\right)}
$$

This formulation implies that a penalty on the intention $I_{i, t}$ exists for women who work, but that this penalty is reduced for those who are more educated. Larger values of $\tau$ imply that more years of education are needed to reduce the penalty. A very large value of $\tau$ implies there is no positive effect of education on the intention to have a child.

Allowing education to have a neutral to positive effect on the intention to have a child, we account for the mechanisms through which having higher educational attainment eases the decision to have a child for a woman who works and has not yet achieved her desired family size. These include the increased ability to outsource childcare, to reduce economic uncertainty, to negotiate the division of housework, and mobilize personal and familial resources to strike a better balance between work and family.

Finally, the last term in equation 2 models how the intention is affected by $d_{i, t}$, the time elapsed since the last birth. In this case, we assume that there is a strong penalty immediately after childbirth that decays over time.

\section{B.3 Conception Risks}

When a couple decides to have a child, their waiting time to conception $w t_{c}$ is determined by their risk of conception. This implies, as in the real world, that a couple's intention is independent of their actual risk, or ability, to conceive. Following earlier models, we represent the risk of conception through the notion of fecundability. In the absence of contraception, fecundability is highest among young couples, and decreases with age as the frequency of intercourse and the biological capacity to conceive decline. 
As we model in continuous time, we define fecundability as the instantaneous risk of conception. We assume it constant, and therefore draw the waiting time to conception from an exponential distribution. Specifically, instantaneous fecundability is defined as:

$$
f_{i, x}=\frac{\phi}{1+\exp \left(\kappa \cdot\left(x_{i}-\gamma\right)\right)}
$$

We fix at $0.22 \mathrm{mo}^{-1}$ the value of $\phi$, the maximum instantaneous fecundability, so as to obtain a 0.93 probability of conceiving within a year $\left(=1-e^{-12 \cdot \phi}\right)$. This corresponds to a monthly fecundability of $0.20\left(=1-e^{-\phi}\right)$, a value consistent with what has been reported in the literature for non contracepting, young couples (Bongaarts and Potter, 1983; Leridon, 2004). Equation 4 specifies that instantaneous fecundability decreases with rate $\kappa$ as the age $x_{i}$ of woman $i$ starts to approach age $\gamma$. The values for $\kappa$ and $\gamma$ were calibrated to fit the pattern of the evolution of fecundability with age proposed by Coale and Trussell (1974).

If the partners decide not to have a child in the next 12 months, they will be at risk of an unplanned conception during this period due to residual fecundability, defined as:

$$
r f_{i, x, t}=f_{i, x} \cdot c_{i, t} \cdot a_{i}
$$

where $c_{i, t} \in[0,1]$ represents the fecundability-reducing effect (effectiveness) of the contraceptive methods available to woman $i$ at time $t . c_{i, t}=0$ represents perfect effectiveness while $c_{i, t}=1$ means complete ineffectiveness. $c_{i, t}$ is defined by:

$$
c_{i, t}=\frac{\left(\rho / y_{i}\right)^{\alpha}}{1+e^{r \cdot\left(t-\left(\psi-y_{i}\right)\right)}}+v
$$

For a given educational attainment level (fixed $y_{i}$ ), the evolution of $c_{i, t}$ through calendar time is simply a decreasing logistic function with maximum value $\left(\rho / y_{i}\right)^{\alpha}$, inflection point $\psi-y_{i}$ and steepness $r$ to which is added a constant $v$, the effectiveness of the best contraceptive methods. This definition reflects the notion that while the effectiveness of contraceptive methods improves over time for all women, better educated women more readily adopt efficient contraceptive methods.

Finally, the last term in equation 5, $a_{i}$ is equal to one if couple $i$ have not yet achieved their desired family size; and fixed value $a$ if the couple have already achieved their desired family size. The assumption here is that the partners will intensify their efforts to prevent additional births after they have reached their goal. 
If the waiting time until conception (planned or unplanned) ${ }_{C} T$ is shorter than 12 months, a waiting time until birth ${ }_{B} T$ is created by adding 270 days of gestation to ${ }_{C} T$. Following the birth, there will be a period of six months that corresponds to the period of postpartum subfecundity, abstinence, and increased contraceptive use with the aim of avoiding dangerously close births. After this period of time, the couple will go back to being exposed to the risk of a new conception.

If no conception occurs within the next 12 months, our couple will update their intentions again at the end of that period. Thus, the partners will either decide to try to have a child in the next year, or they will be subject to the risk of an unplanned birth.

\section{B.4 Age at union formation}

To keep things simple, the preferences, intentions, and risks that control the process described so far are assumed to operate only after the formation of a cohabitation union. The age at which this event occurs is therefore of considerable importance. We follow previous studies that have successfully approached the empirical distribution in the age at marriage using the log-normal distribution (Mode, 1985).

$$
\ln \left(M_{i}\right) \sim \mathcal{N}\left(\mu_{i}, \sigma^{2}\right)
$$

with $\mu_{i}=y_{i}+\xi$, where $y_{i}$ is the numbers of years of education of woman $i$, and parameter $\xi$ is the average waiting time (in years) to the formation of a cohabiting union after the end of the schooling period.

\section{B.5 Death}

The waiting time until death is sampled using the inverse distribution function method (for a description of the method see: Willekens, 2009), where the distribution of waiting times until death is reconstructed using age-specific cohort mortality rates available at (HMD, 2015).

\section{B.6 Pseudo code}

Most earlier computational models were built on a discrete time framework in which time advances at arbitrary and equally spaced time units, and the state of the system is updated at each of these iterations. We use a discrete event framework (Zeigler et al., 2000) in which time advances with the realization of events. At each iteration, the algorithm finds the event with the shortest waiting time from a list of all possible events for the entire population of simulated individuals. After the realization of the next event, the state of the system and the clock are updated, and the simulation can continue 
to the next run. In demography this approach is known as microsimulation in continuous time (see: Willekens, 2009).

The pseudo-code below describes the basic operation of Comfert. The entire process is described by four events: starting a cohabiting union, considering whether to have a child, having a child, and death. 


\section{The Comfert algorithm}

\section{read input data}

educational attainment (cohort)

labor force participation by edu. (cohort)

initialization

generate wts to birth in the first year

While time < end time do

choose next event $\rightarrow$ n_event

update clock

update ages \& waiting times

if $n \_$event $=$birth then

if girl then

add to population

assign:

educational attainment

years in education

labor force participation

wt to union

wt to death

wt to evaluate $==\operatorname{Inf}$

end

update indicators of mother:

age at birth

nr. children

nr. children left

wt to evaluate

end

if $n \_$event $=$death then

remove from the population

end

(continues at top of right column) if $n \_$event $=$union formation then

assign desired family size $D_{i}$

compute intention $I_{i, t}$

if $I_{i, t}>x \sim U(0,1)$ then wt conception $\rightarrow f_{i, x}$

else

| wt conception $\rightarrow r f_{i, x, t}$

end

if $w t$ conception $>1$ year then wt evaluate $==1$ year

end

end

if n.event $=$ evaluate then

update intention $I_{i, t}$

if $I_{i, t}>x \sim U(0,1)$ then wt conception $\rightarrow f_{i, x}$

else

| wt conception $\rightarrow r f_{i, x, t}$

end

if $w t$ conception $>1$ year then wt evaluate $==1$ year

end

end

if year change then

remove those with age $>$ max_age

compute indicators.

end

end While

save output

age specific fert. rates; unplanned births;

desired fam. size.

end

$w t=$ Waiting time; $n \_$event $=$next event $;$max_age $=$age at end of reproductive period (50); end time = Last year for which model is run; $f=$ Fecundability; $r f=$ Residual Fecundability 


\section{B.7 Estimated Parameter Values}

\begin{tabular}{|c|c|c|c|c|c|}
\hline Name & Domain & Eq. & Description & Value & Source \\
\hline$\delta$ & desired fam. size & 1 & effect on $D_{i}$ of working & 0.008 & estimated \\
\hline$\beta$ & intention & 2 & baseline intention & 0.8 & fixed \\
\hline$\lambda$ & intention & 2 & rate of reduction penalty after pregnancy & $2.5 \mathrm{e}-8 \mathrm{~s}^{-1}$ & fixed \\
\hline$\eta$ & intention & 3 & penalty on intention of working & 0.57 & estimated \\
\hline$\tau$ & intention & 3 & years of edu. after which $\eta$ is reduced & $25.6 \mathrm{yr}$ & estimated \\
\hline$\epsilon$ & intention & 3 & speed at which $\eta$ is reduced & $0.53 \mathrm{yr}^{-1}$ & fixed \\
\hline$\phi$ & fecundability & 4 & maximum fecundability & $0.22 \mathrm{mo}^{-1}$ & fixed \\
\hline$\gamma$ & fecundability & 4 & inflection point of decline (age) & $38 \mathrm{yr}$ & fixed \\
\hline$\kappa$ & fecundability & 4 & speed of decline with age & $0.25 \mathrm{yr}^{-1}$ & fixed \\
\hline$A$ & contraception & 5 & additional effect due to achieved $D$ & 0.07 & fixed \\
\hline$\rho$ & contraception & 6 & governs minimum effect on conception risk & 0.04 & estimated \\
\hline$v$ & contraception & 6 & maximum effect on conception risk & 0.03 & estimated \\
\hline$\psi$ & contraception & 6 & inflection year in the diffusion process & 1977 & estimated \\
\hline$r$ & contraception & 6 & speed of the diffusion & $0.23 \mathrm{yr}^{-1}$ & estimated \\
\hline$\alpha$ & contraception & 6 & differential access/use by education & 0.07 & estimated \\
\hline$\xi$ & age union form. & 7 & time to union after schooling & $4.61 \mathrm{yr}$ & estimated \\
\hline
\end{tabular}

Table 1 I Model parameters and best-fitting values - Norway. The baseline intention $\beta$ was set a value lower than one 1 to consider other effects not explicitly modelled that might impose a penalty on the intention. Estimates for $\gamma$ and $\kappa$ were derived from the scheduled developed by (Coale and Trussel1, 1974). Estimates for the rest of the fixed parameters were obtained by calibration. 


\section{Appendix}

\section{C.1 Regression Model Results}

\begin{tabular}{|c|c|c|c|c|c|}
\hline & \multicolumn{5}{|c|}{$2^{\text {nd }}$ Births } \\
\hline & $\begin{array}{c}\text { Cohort } 1940-4 \\
(1) \\
\end{array}$ & $\begin{array}{c}\text { Cohort } 1945-9 \\
\text { (2) } \\
\end{array}$ & $\begin{array}{c}\text { Cohort } 1950-4 \\
(3)\end{array}$ & $\begin{array}{c}\text { Cohort } 1955-9 \\
\text { (4) } \\
\end{array}$ & $\begin{array}{c}\text { Cohort } 1960-4 \\
(5) \\
\end{array}$ \\
\hline Age knot - 1 & $\begin{array}{l}0.466^{* * *} \\
(0.070)\end{array}$ & $\begin{array}{l}0.357^{* * *} \\
(0.064)\end{array}$ & $\begin{array}{l}0.361^{* * *} \\
(0.062)\end{array}$ & $\begin{array}{l}0.542^{* * *} \\
(0.052)\end{array}$ & $\begin{array}{l}0.680^{* * * *} \\
(0.050)\end{array}$ \\
\hline Age knot - 2 & $\begin{array}{c}0.331 \\
(0.225)\end{array}$ & $\begin{array}{l}0.445^{* * *} \\
(0.131)\end{array}$ & $\begin{array}{l}0.394^{* * *} \\
(0.089)\end{array}$ & $\begin{array}{l}0.494^{* * *} \\
(0.071)\end{array}$ & $\begin{array}{l}0.580^{* * * *} \\
(0.064)\end{array}$ \\
\hline Duration knot - 1 & $\begin{array}{l}3.558^{* * *} \\
(0.027)\end{array}$ & $\begin{array}{l}3.630^{* * *} \\
(0.028)\end{array}$ & $\begin{array}{l}3.664^{* * *} \\
(0.029)\end{array}$ & $\begin{array}{l}3.588^{* * *} \\
(0.030)\end{array}$ & $\begin{array}{l}3.660^{* * *} \\
(0.032)\end{array}$ \\
\hline Duration knot - 2 & $\begin{array}{l}3.425^{* * *} \\
(0.043)\end{array}$ & $\begin{array}{l}3.780^{* * *} \\
(0.039)\end{array}$ & $\begin{array}{l}4.778^{* * *} \\
(0.035)\end{array}$ & $\begin{array}{l}5.101^{* * *} \\
(0.033)\end{array}$ & $\begin{array}{l}5.713^{* * *} \\
(0.034)\end{array}$ \\
\hline Duration knot - 3 & $\begin{array}{l}1.276^{* * *} \\
(0.092)\end{array}$ & $\begin{array}{l}2.121^{* * *} \\
(0.068)\end{array}$ & $\begin{array}{l}3.447^{* * *} \\
(0.051)\end{array}$ & $\begin{array}{l}4.196^{* * *} \\
(0.044)\end{array}$ & $\begin{array}{l}4.537^{* * *} \\
(0.043)\end{array}$ \\
\hline Duration knot - 4 & $\begin{array}{l}0.541^{* * *} \\
(0.149)\end{array}$ & $\begin{array}{l}1.098^{* * *} \\
(0.108)\end{array}$ & $\begin{array}{l}2.114^{* * *} \\
(0.077)\end{array}$ & $\begin{array}{l}2.750^{* * *} \\
(0.062)\end{array}$ & $\begin{array}{l}3.197^{* * *} \\
(0.057)\end{array}$ \\
\hline Duration knot - 5 & $\begin{array}{c}0.004 \\
(0.855)\end{array}$ & $\begin{array}{c}0.0003 \\
(0.883)\end{array}$ & $\begin{array}{c}0.001 \\
(0.638)\end{array}$ & $\begin{array}{c}0.003 \\
(0.466)\end{array}$ & $\begin{array}{c}0.006 \\
(0.382)\end{array}$ \\
\hline Secondary Education & $\begin{array}{l}0.855^{* * *} \\
(0.025)\end{array}$ & $\begin{array}{l}0.794^{* * *} \\
(0.024)\end{array}$ & $\begin{array}{l}0.759^{* * *} \\
(0.023)\end{array}$ & $\begin{array}{l}0.836^{* * *} \\
(0.022)\end{array}$ & $\begin{array}{l}0.926^{* * *} \\
(0.022)\end{array}$ \\
\hline Tertiary Education & $\begin{array}{l}0.559^{* * *} \\
(0.034)\end{array}$ & $\begin{array}{l}0.614^{* * *} \\
(0.032)\end{array}$ & $\begin{array}{l}0.705^{* * *} \\
(0.029)\end{array}$ & $\begin{array}{l}0.876^{* * *} \\
(0.026)\end{array}$ & $\begin{array}{l}1.002^{* * *} \\
(0.025)\end{array}$ \\
\hline Constant & $\begin{array}{l}0.468^{* * *} \\
(0.041)\end{array}$ & $\begin{array}{l}0.429^{* * *} \\
(0.038)\end{array}$ & $\begin{array}{l}0.323^{* * *} \\
(0.041)\end{array}$ & $\begin{array}{l}0.180^{* * *} \\
(0.038)\end{array}$ & $\begin{array}{l}0.119^{* * * *} \\
(0.040)\end{array}$ \\
\hline Observations & 21,762 & 27,147 & 38,284 & 49,243 & 55,183 \\
\hline Log Likelihood & $-12,466.100$ & $-15,141.490$ & $-20,820.790$ & $-26,044.040$ & $-28,130.190$ \\
\hline Akaike Inf. Crit. & $24,952.200$ & $30,302.970$ & $41,661.580$ & $52,108.090$ & $56,280.390$ \\
\hline
\end{tabular}

Table 2 I Hazard Regression Model Results - Simulated Data 


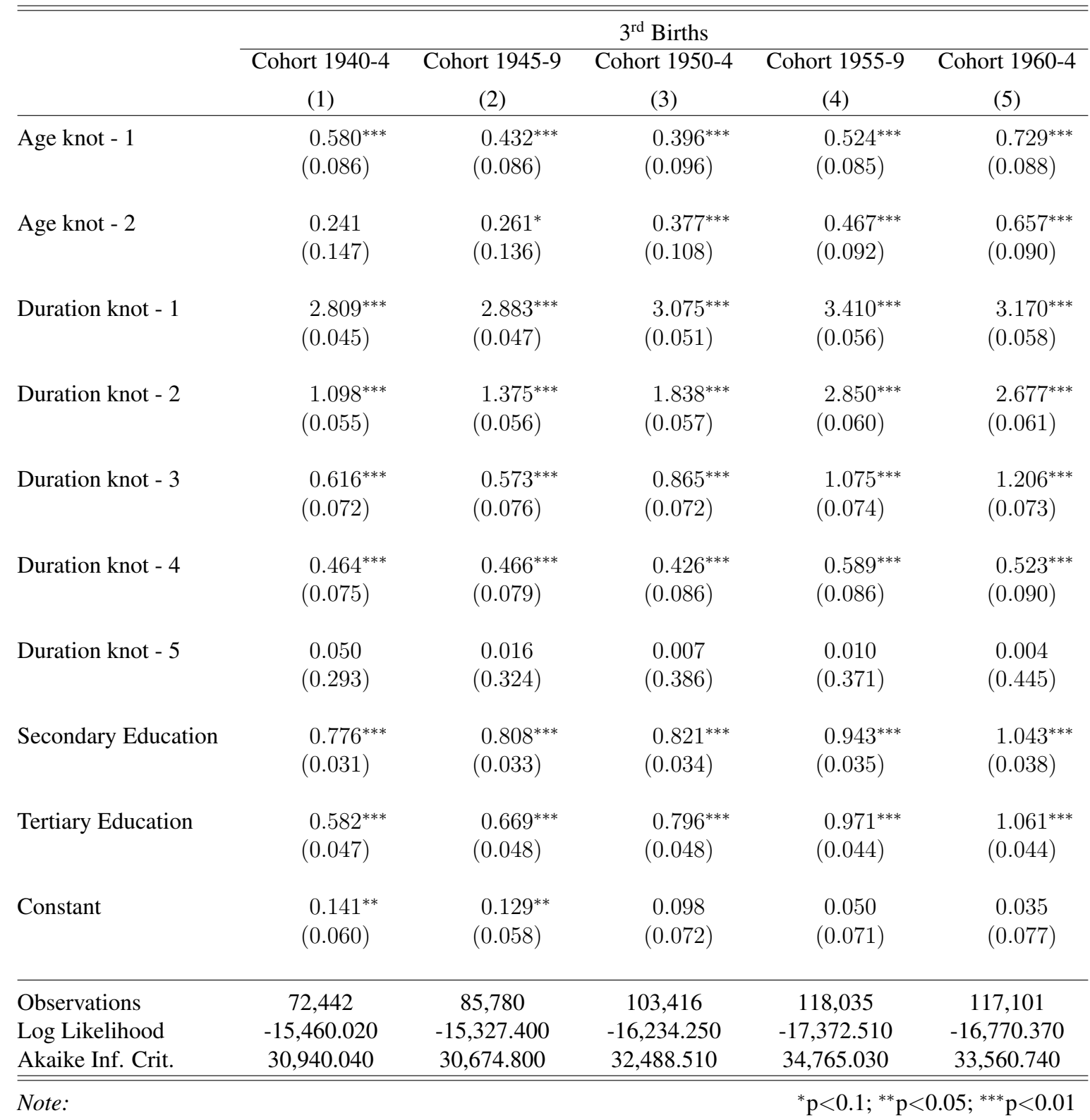

Table 3 I Hazard Regression Model Results - Simulated Data 


\section{References}

Ahn, N. and P. Mira (2002). A note on the changing relationship between fertility and female employment rates in developed countries. Journal of population Economics 15(4), 667-682.

Beaumont, M. A. (2010). Approximate bayesian computation in evolution and ecology. Annual review of ecology, evolution, and systematics 41, 379-406.

Beaumont, M. A. (2019). Approximate bayesian computation. Annual review of statistics and its application 6, 379-403.

Becker, G. S. (1960). An economic analysis of fertility. In Demographic and economic change in developed countries, pp. 209-240. Columbia University Press.

Becker, G. S. and H. G. Lewis (1973). On the interaction between the quantity and quality of children. Journal of political Economy 81(2, Part 2), S279-S288.

Becker, G. S. and N. Tomes (1976). Child endowments and the quantity and quality of children. Journal of political Economy 84(4, Part 2), S143-S162.

Berrington, A. and S. Pattaro (2014). Educational differences in fertility desires, intentions and behaviour: A life course perspective. Advances in life course research 21, 10-27.

Bongaarts, J. (1990). The measurement of wanted fertility. Population and development review, 487-506.

Bongaarts, J. (1997). Trends in unwanted childbearing in the developing world. Studies in Family planning, 267-277.

Bongaarts, J. (2001). Fertility and reproductive preferences in post-transitional societies. Population and Development Review 27, 260-281.

Bongaarts, J. (2003). Completing the fertility transition in the developing world: The role of educational differences and fertility preferences. Population Studies 57(3), 321-335.

Bongaarts, J. and R. E. Potter (1983). Fertility, biology, and behavior: An analysis of the proximate determinants. Academic Press.

Boonstra, H. D., R. B. Gold, C. L. Richards, and L. B. Finer (2006). Abortion in women's lives.

Caltabiano, M., M. Castiglioni, A. Rosina, et al. (2009). Lowest-low fertility: Signs of a recovery in Italy. Demographic research 21(23), 681-718. 
Castiglioni, M., G. Dalla Zuanna, and M. Loghi (2001). Planned and unplanned births and conceptions in italy, 1970-1995. European Journal of Population/Revue européenne de Démographie 17(3), 207-233.

Coale, A. J. and T. J. Trussell (1974). Model fertility schedules: variations in the age structure of childbearing in human populations. Population index, 185-258.

Cochrane, S. H. (1979). Fertility and education: What do we really know?

Dancik, G. M. and K. S. Dorman (2008). mlegp: statistical analysis for computer models of biological systems using r. Bioinformatics 24(17), 1966-1967.

De Wachter, D. and K. Neels (2011). Educational differentials in fertility intentions and outcomes: family formation in flanders in the early 1990s. Vienna Yearbook of Population Research, 227-258.

Doepke, M. (2015). Gary becker on the quantity and quality of children. Journal of Demographic Economics 81(1), 59-66.

Easterlin, R. A. and E. M. Crimmins (1985). The fertility revolution: A supply-demand analysis. University of Chicago Press.

Esping-Andersen, G. and F. C. Billari (2015). Re-theorizing family demographics. Population and Development Review 41(1), 1-31.

Finer, L. B. and S. K. Henshaw (2006). Disparities in rates of unintended pregnancy in the united states, 1994 and 2001. Perspectives on sexual and reproductive health 38(2), 90-96.

Galor, O. (2011, May). The demographic transition: Causes and consequences. Working Paper 17057, National Bureau of Economic Research.

Gutmann, M. U. and J. Corander (2016). Bayesian optimization for likelihood-free inference of simulator-based statistical models. The Journal of Machine Learning Research 17(1), 4256-4302.

Henshaw, S. K. (1998). Unintended pregnancy in the united states. Family planning perspectives, $24-46$.

HMD (2015). Human Mortality Database. University of California, Berkeley (USA), and Max Planck Institute for Demographic Research (Germany). Available at www.mortality.org or www.humanmortality.de (data downloaded on May 2015).

Hoem, B. and J. M. Hoem (1989). The impact of women's employment on second and third births in modern sweden. Population Studies 43(1), 47-67. 
Human Fertility Database, . (2011). Human fertility database.

Jones, L. E., A. Schoonbroodt, and M. Tertilt (2008). Fertility theories: can they explain the negative fertility-income relationship? Technical report, National Bureau of Economic Research.

Klijzing, E. (2000). Are there unmet family planning needs in europe? Family planning perspectives, $74-88$.

Kravdal, Ø. (1992). The emergence of a positive relation between education and third birth rates in norway with supportive evidence from the united states. Population studies 46(3), 459-475.

Kravdal, Ø. (2001). The high fertility of college educated women in norway: An artefact of the separate modelling of each parity transition. Demographic research 5, 187-216.

Kravdal, Ø. and R. R. Rindfuss (2008). Changing relationships between education and fertility: A study of women and men born 1940 to 1964. American Sociological Review 73(5), 854-873.

Kreyenfeld, M. (2002). Time-squeeze, partner effect or self-selection? an investigation into the positive effect of women's education on second birth risks in west germany. Demographic research 7, $15-48$.

Leridon, H. (2004). Can assisted reproduction technology compensate for the natural decline in fertility with age? a model assessment. Human Reproduction 19(7), 1548-1553.

Luci-Greulich, A. and O. Thévenon (2014). Does economic advancement 'Cause'a re-increase in fertility? An empirical analysis for OECD countries (1960-2007). European Journal of Population 30(2), 187-221.

Mode, C. J. (1985). Stochastic processes in demography and their computer implementation, Volume 14. Springer Science \& Business Media.

Murphy, M. (1993). The contraceptive pill and women's employment as factors in fertility change in britain 1963-1980: A challenge to the conventional view. Population studies 47(2), 221-243.

Musick, K., P. England, S. Edgington, and N. Kangas (2009). Education differences in intended and unintended fertility. Social Forces 88(2), 543-572.

Myrskylä, M., H.-P. Kohler, and F. C. Billari (2009). Advances in development reverse fertility declines. Nature 460(7256), 741-743.

R Core Team (2015). R: A Language and Environment for Statistical Computing. Vienna, Austria: R Foundation for Statistical Computing. 
Régnier-Loilier, A., H. Leridon, F. Cahen, et al. (2007). Four decades of legalized contraception in france: an unfinished revolution? Technical report, Institut National d'Études Démographiques (INED).

Rindfuss, R. R. and K. L. Brewster (1996). Childrearing and fertility. Population and Development Review 22, 258-289.

Sobotka, T. and É. Beaujouan (2014). Two Is Best? The Persistence of a Two-Child Family Ideal in Europe. Population and Development Review 40(3), 391-419.

Testa, M. R. (2014). On the positive correlation between education and fertility intentions in europe: Individual-and country-level evidence. Advances in life course research 21, 28-42.

Willekens, F. (2009). Continuous-time microsimulation in longitudinal analysis. New frontiers in microsimulation modelling, 353-376.

Wulf, D. (1982). Low fertility in europe: A report from the 1981 iussp meeting. Family planning perspectives 14(5), 264-270.

Zeigler, B. P., T. G. Kim, and H. Praehofer (2000). Theory of modeling and simulation. Academic press.

Zeman, K., Z. Brzozowska, T. Sobotka, É. Beaujouan, and A. Matysiak (2014). Cohort fertility and education database. methods protocol. 